\title{
HER-2 ONCOPROTEIN EXPRESSION IN UROTHELIAL CARCINOMA
}

\author{
Surinder Kumar Atri' ${ }^{1}$ Virender Mohan Rana², Rahul Gupta ${ }^{3}$ \\ ${ }^{1}$ Associate Professor, Department of Pathology, Government Medical College, Jammu, Jammu and Kashmir. \\ ${ }^{2}$ Demonstrator, Department of Pathology, Government Medical College, Jammu, Jammu and Kashmir. \\ ${ }^{3}$ Associate Professor, Department of Urology, Government Medical College, Jammu, Jammu and Kashmir.
}

\section{ABSTRACT}

\section{BACKGROUND}

Low grade non-muscle invasive transitional cell carcinoma is associated with repeated recurrences and progression to high grade tumour. Non-muscle invasive transitional cell carcinoma is associated with poor oncological outcome. Therefore, this study was undertaken to evaluate the expression of HER-2 oncoprotein in transitional cell carcinoma and further to evaluate whether expression of this oncoprotein has relation with grade of tumour and invasion of muscle.

The objective of this study is to evaluate the expression of HER-2 protein in low grade, high grade and muscle invasive transitional cell carcinoma using immunohistochemistry.

\section{MATERIALS AND METHODS}

It was a retrospective, descriptive study of duration of three years in which all cases of transitional cell carcinoma signed out in the Department of Pathology from January 2012 to December 2014 were included. All cases of transitional cell carcinoma signed out in the above-mentioned period were retrieved from surgical pathology files and consult files of Govt. Medical College, Jammu. Sample size was conveniently taken. In total, 104 cases were identified over a period of three years. Haematoxylin and eosin stained sections of $5 \mu \mathrm{m}$ thickness were re-examined in all cases to confirm the diagnosis and grade the tumour. Immunohistochemistry for HER-2 protein was done in ten cases, each of low and high grade transitional cell carcinoma. Immunohistochemistry was also done in tumours invading muscle (18 cases). Clinical features and followup data was obtained from consult files and referring surgeons. Statistical analysis was performed using SPSS 10.0 for Windows student version (SPSS Inc., 233 South Wacker Drive, 11th Floor, Chicago, IL 60606-6412). Statistical tool like Fisher exact test was applied. This study was approved by Institutional Ethics Committee of Govt. Medical College, Jammu.

\section{RESULTS}

Age of the patients ranged from 22 to 86 years and mean age was 59.28 years. The common clinical presentation was haematuria (96.7\%). Of total 104 cases, 83 (79.8\%) were papillary urothelial carcinoma low grade and 21 (20.19\%) were papillary urothelial high grade. Eighteen cases $(17.30 \%)$ showed muscle invasion; 8 (80\%) of ten cases of low grade papillary urothelial carcinoma were positive for HER-2. Six (60\%) cases of high grade papillary urothelial carcinoma were positive HER-2; 14 (77.77\%) of the 18 cases associated with muscle invasion showed HER-2 oncoprotein expression.

\section{CONCLUSION}

About three-quarters of urothelial carcinoma overexpress HER-2 and this is very promising for molecular targeted therapy and moreover HER-2 overexpression also has prognostic and diagnostic significance. We propose that immunohistochemistry for HER2 protein should be incorporated into the routine surgical pathology sign-out of urothelial carcinoma.

\section{KEYWORDS}

Urothelial Carcinoma, Erb, HER-2/Neu, Molecular Targeted Therapy.

HOW TO CITE THIS ARTICLE: Atri SK, Rana VM, Gupta R. HER-2 oncoprotein expression in urothelial carcinoma. J. Evolution Med. Dent. Sci. 2017;6(87):5985-5990, DOI: 10.14260/jemds/2017/1302

\begin{abstract}
BACKGROUND
Urinary bladder cancer accounts for approximately 7\% of all cancers and $3 \%$ of mortality by cancer is because of cancers of urinary bladder. ${ }^{1}$ Malignancies of urinary bladder is the fourth most common cancer in men after carcinoma of prostate, lung and colon. ${ }^{1}$ Mortality wise malignancies of urinary bladder is the eighth leading cause of mortality in men. ${ }^{1}$
\end{abstract}

'Financial or Other Competing Interest': None.

Submission 21-09-2017, Peer Review 18-10-2017,

Acceptance 24-10-2017, Published 30-10-2017.

Corresponding Author:

Dr. Surinder Kumar Atri,

Associate Professor,

House No. 24, Lane 51; Behind Sunny Farms,

Greater Kailash Post Office: Gangyal, Jammu-180010,

Jammu and Kashmir

E-mail: surinderkumaratri@gmail.com

DOI: $10.14260 /$ jemds $/ 2017 / 1302$
In females, malignancies of urinary bladder are quite common and male-female ratio is 3:1.1 Most common histologic type of bladder cancer is urothelial carcinoma or transitional cell carcinoma, which accounts for more than $90 \%$ of bladder cancers. Papillary urothelial carcinoma is divided into low grade and high grade as per classification jointly proposed by World Health Organisation and the International Society of Urinary Pathology [WHO/ISUP].2,3,4 Main features of this classification is the division of neoplastic lesions of bladder into papillary and flat and separate evaluation of papillary lesions for grade and invasiveness. These tumours are divided into low and high grade based on architecture and cytology. Invasiveness is evaluated whether tumour is invading into lamina propria or muscularis propria; $75 \%-80 \%$ of urothelial carcinoma present as nonmuscle invasive disease. ${ }^{5}$ Low grade non-muscle invasive transitional cell carcinoma is characterised by repeated recurrences and progression to high grade transitional cell 
carcinoma. ${ }^{6}$ Management of non-muscle invasive transitional cell carcinoma is a major problem in clinical practice. Nonmuscle invasive transitional cell carcinoma is associated with poor oncological outcome. Cormio et $\mathrm{al}^{7}$ in a study of 153 patients with T1G3 disease stated, one-third of these patients are cured and does not show any recurrence or progression of disease. Another one-third show recurrence and undergo deferred radical cystectomy. Remaining one-third eventually die of disease. At diagnosis, $30 \%$ of all cases of transitional cell carcinoma of bladder present as muscle invasive disease. ${ }^{8}$ Muscle invasive tumours may extend to prostate, seminal vesicle, ureters and retroperitoneum; $40 \%$ of muscle invasive tumours metastasise to regional lymph nodes and haematogenous dissemination can also occur.6,9 Despite advances in treatment over past decades, advanced urothelial carcinoma is frequently lethal and improvements in cytotoxic chemotherapy have plateaued.10,11 Management of advanced urothelial carcinoma along with outcome has remained largely unchanged for the past two decades.12,13 In recent years, molecularly targeted therapies have been integrated into the standard of care management of solid tumours like carcinoma breast and adenocarcinoma lung. However, targeted therapies have lagged behind in treatment of urothelial carcinoma. ${ }^{8}$ Preclinical and early clinical studies have demonstrated numerous potentially targetable molecular pathways in urothelial carcinoma. The Cancer Genome Atlas study revealed that there are numerous genomic aberrations in urothelial carcinoma of bladder such as TP53, ARID 1A, PIKCA, ERCC2, FGFR and HER-2.8 We therefore undertook this study to evaluate the expression of HER-2 oncoprotein transitional cell carcinoma using immunohistochemistry.

\section{MATERIALS AND METHODS}

It was a retrospective, descriptive study of duration of three years in which all cases of transitional cell carcinoma signed out in the Department of Pathology from January 2012 to December 2014 were included. All cases of transitional cell carcinoma signed out in the above-mentioned period were retrieved from surgical pathology files and consult files of Govt. Medical College, Jammu. Sample size was conveniently taken. In total, 104 cases were identified over a period of three years. Haematoxylin and eosin stained sections of $5 \mu \mathrm{m}$ thickness were re-examined in all cases to confirm the diagnosis and grade the tumour. Immunohistochemistry for HER-2 protein was done in ten cases, each of low and high grade transitional cell carcinoma. Immunohistochemistry was also done in tumours invading muscle (18 cases). Clinical features and followup data was obtained from consult files and referring surgeons.

Statistical analysis was performed using SPSS 10.0 for Windows student version (SPSS Inc., 233 South Wacker Drive, 11th Floor, Chicago, IL 60606-6412). Statistical tool like Fisher exact test was applied. This study was approved by Institutional Ethics Committee of Govt. Medical College, Jammu.

\section{Immunohistochemistry}

Immunohistochemistry was done using streptavidin biotin conjugate (LSAB) immunoperoxidase technique on formalinfixed, paraffin-embedded one representative cross-sectional slide per tumour, displaying a maximum of tumour mass. The monoclonal antibodies were obtained from M/S Novocastra Laboratories, Newcastle upon Tyne, UK. The LSAB kit was obtained from M/S DakoPatts, Denmark. Her-2 protein expression per cross-sectional slide was interpreted according to Lacombe et al; considered positive if more than $20 \%$ of the tumour cells were positive and negative if less than $20 \%$ of tumour cells were positive.

\section{RESULTS}

The age of patients varied from 22 to 86 years and mean age was 59.28 years. The common clinical presentation was haematuria (97.7\%). Of total 104 cases 83 (79.8\%) were papillary urothelial carcinoma, low grade and 21 (20.19\%) were papillary urothelial carcinoma of high grade. Eighteen cases $(17.30 \%)$ showed muscle invasion; $8(80 \%)$ of ten cases of low grade TCC were positive for HER-2. Six (60\%) cases of high grade TCC were positive for HER-2; 14 (77.7\%) of the 18 cases associated with muscle invasion showed HER-2 positivity.

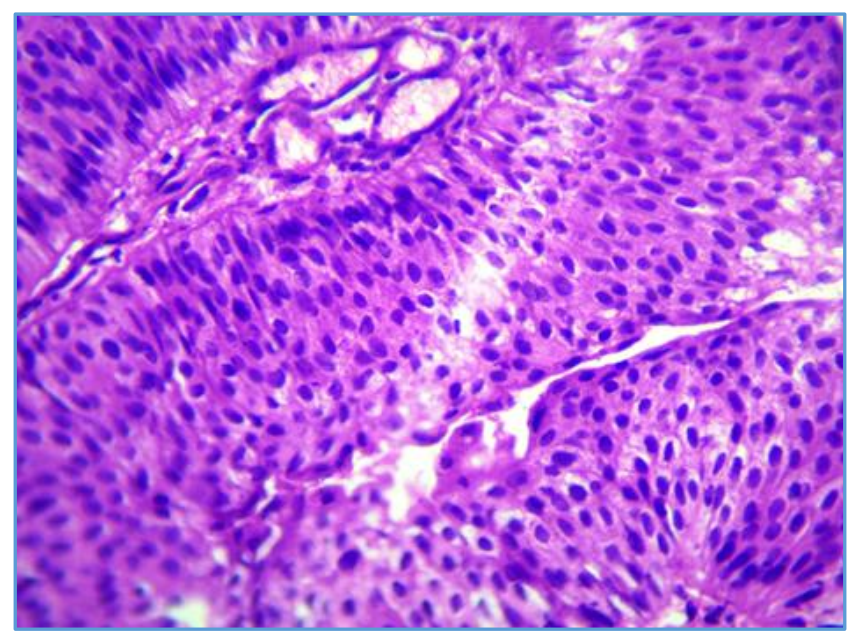

Figure 1. Microphotograph of Low-Grade Papillary Urothelial Carcinoma [H and E $200 \mathrm{x}$ ]

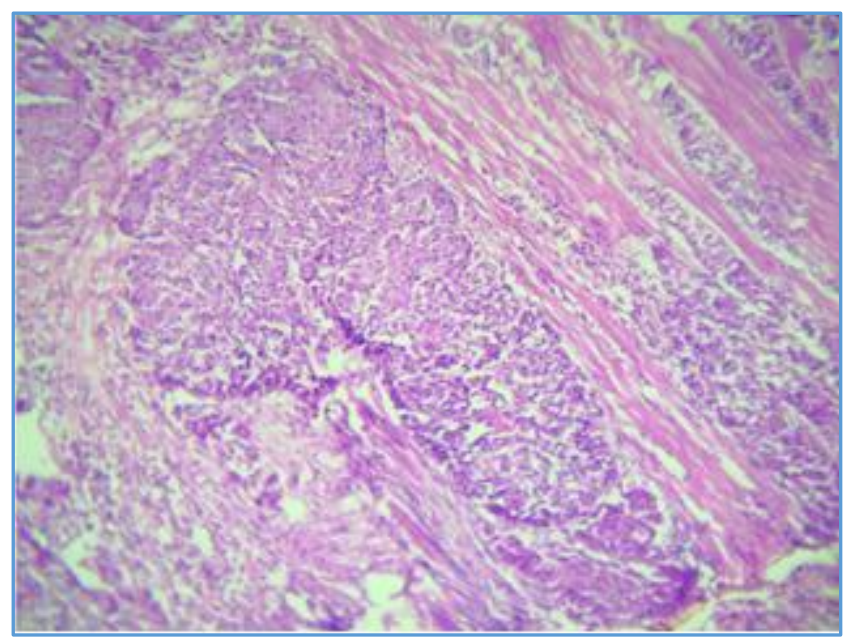

Figure 2. Microphotograph of Low Grade Papillary Urothelial Carcinoma Infiltrating into Muscle [H and E $100 \mathrm{x}$ ] 


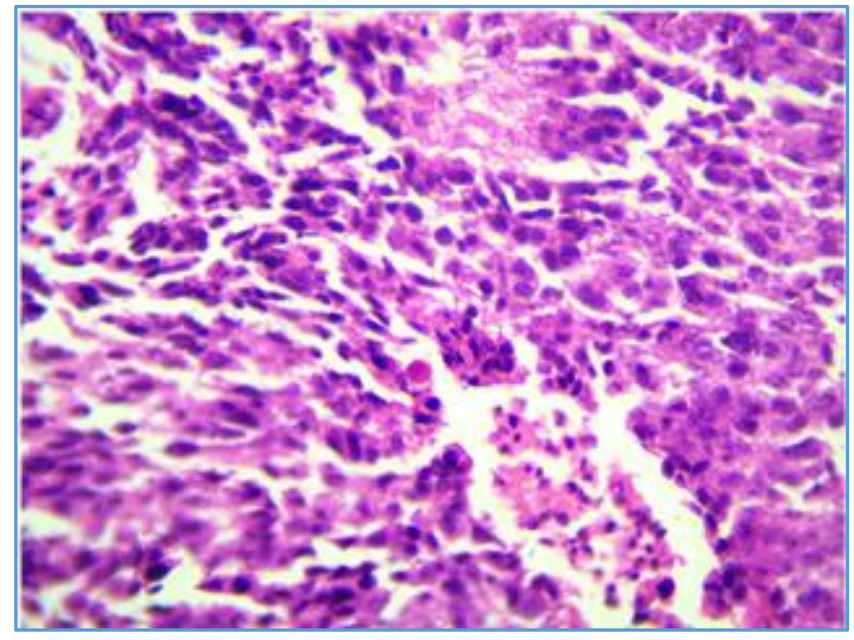

Figure 3. Microphotograph of High Grade Papillary Urothelial Carcinoma [H and E $100 \mathrm{x}$ ]

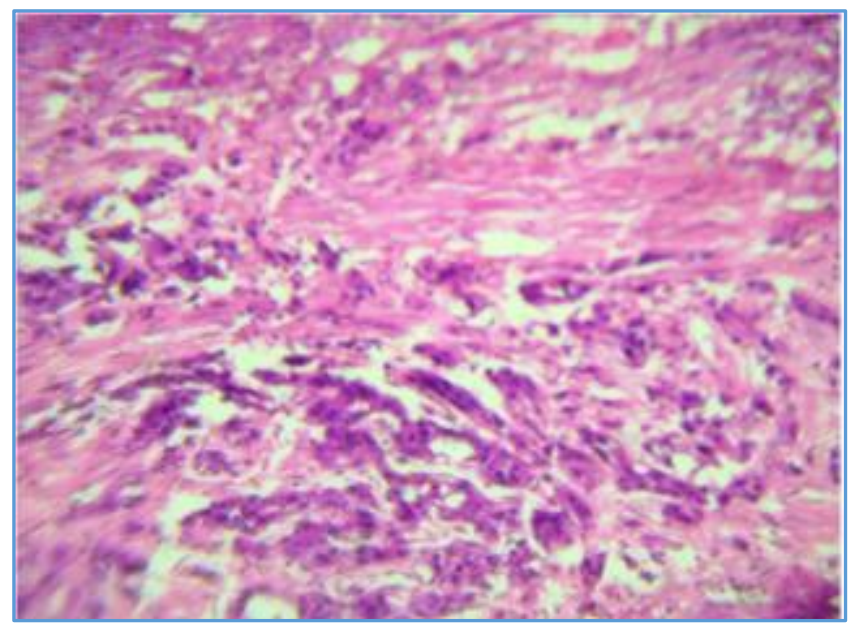

Figure 4. Microphotograph of High Grade Papillary Urothelial Carcinoma [H and $E 100 \mathrm{x}$ ]

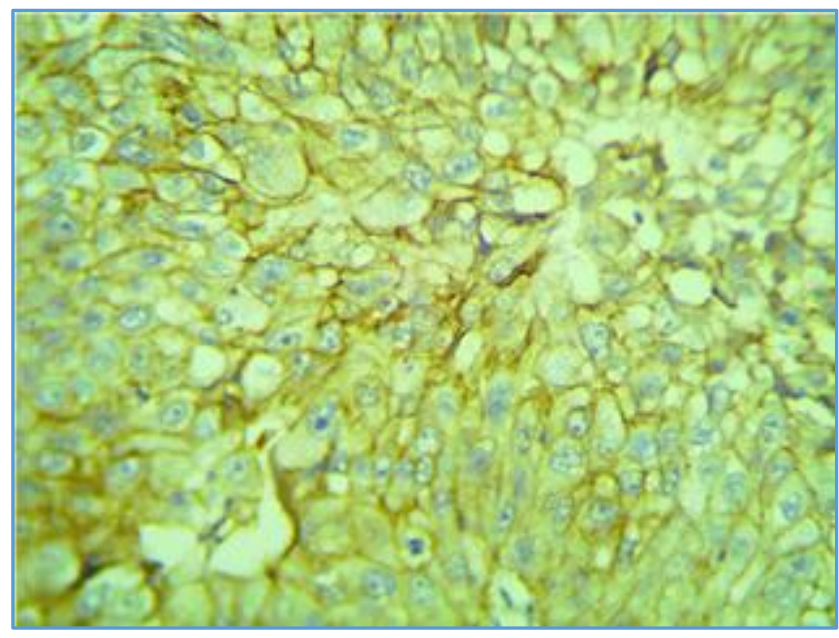

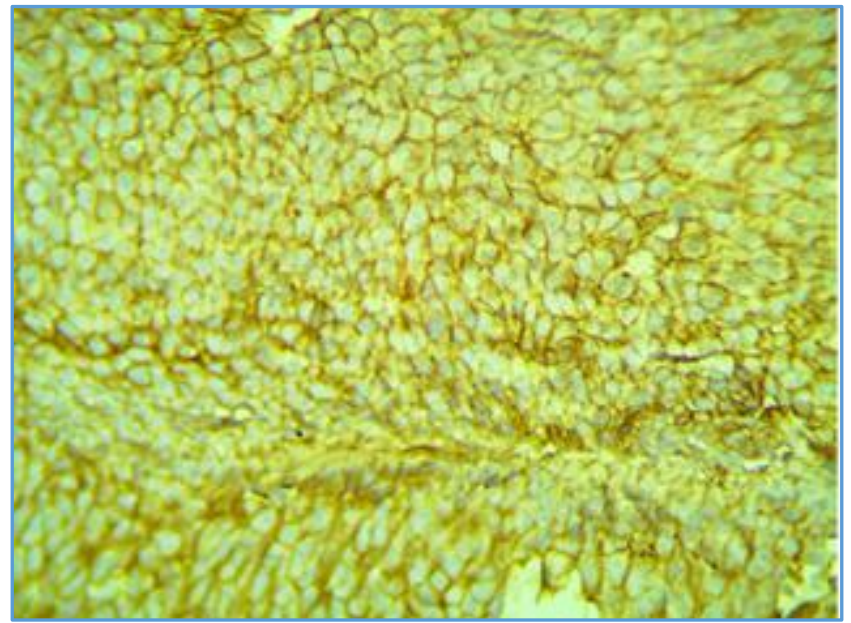

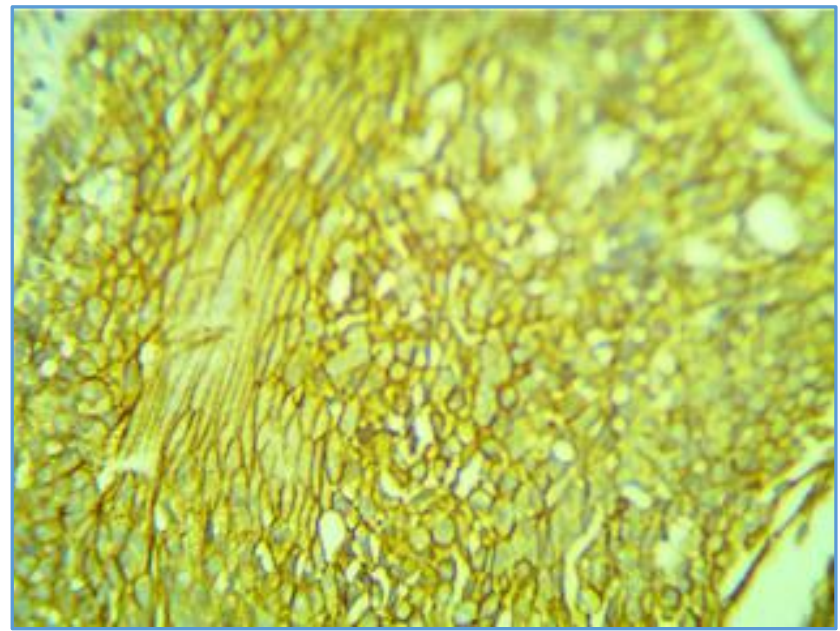

Figure 5, Figure 6 and Figure 7. Immunohistochemistry for HER-2 in Case of Transitional Cell Carcinoma showing Strong Cell Membrane Positivity [100x]

\section{DISCUSSION}

HER-2 is a receptor tyrosine kinase that belong to Group I of 20 families of receptor tyrosine kinases. ${ }^{14}$ Other members of this group are HER-1 (Erb-B1), HER-3 (Erb-B3) and HER-4 (Erb-B4). These tyrosine kinases are encoded by gene Erb-B located on chromosome 17q2115 (Erb-B1, Erb-B2, Erb-B3 and Erb-B4). We know that receptor tyrosine kinases are transmembrane proteins with an extracellular ligand binding domain and a cytoplasmic domain. Receptor tyrosine kinase is activated transiently by binding of a specific growth factor to the extracellular domain, an event that induces homo- or heterodimerisation. ${ }^{16}$ This activation leads to downstream signaling via a number of pathways including RAS, PI3K, etc. This results in cellular proliferation and survival. Oncogenic changes in these receptors may be because of mutations, gene amplification or gene rearrangement leading to constitutive growth factor independent of tyrosine kinase activity. Hence, oncogenic tyrosine kinase receptor delivers continuous signal to the cell for cellular proliferation, ${ }^{17}$ inhibition of apoptosis ${ }^{18}$ and promote angiogenesis. ${ }^{19}$ 
HER-1 or EGFR is over expressed in a subset of adenocarcinoma lung and mechanism involved is point mutation of Erb-B1 gene. Molecularly targeted therapy is available for this subset of adenocarcinoma, lung. ${ }^{20}$

HER-2 is also overexpressed in malignancies of various other organs, which are characteristically very aggressive. ${ }^{20}$ For the first time, HER-2 overexpression was described in carcinoma breast $^{21}$ and mechanism underlying this overexpression is amplification of Erb-B2 gene. Anti-HER-2 therapy is well established in treatment of carcinoma breast ${ }^{22}$ and this has assumed more significance with molecular classification of carcinoma breast. Incidence of HER-2 expression in urothelial carcinoma and carcinoma stomach ${ }^{23}$ are not well established. HER-2 protein overexpression seen in transitional cell carcinoma of bladder varies in different studies from $9 \%-81 \% .24,25,26,27,28$ In our study the incidence of HER-2 overexpression was $74 \%, 80 \%$ in low grade, $60 \%$ in high grade and $78 \%$ in muscle invasive urothelial tumours. The number of cases are very few in each group. Reason for this wide range of HER-2 positivity [ $9 \%-81 \%]$ is that studies which include new freshly diagnosed cases show high incidence, whereas studies which included recurrent, advanced and metastatic cases show low overexpression of HER-2. ${ }^{29,30,31}$ Therefore, HER-2 overexpression is more in low grade TCCs as compared to high grade, recurrent tumours and this expression is variable in muscle invasive tumours. Morgan et $\mathrm{al}^{32}$ reported that BCG adjuvant therapy in nonmuscle invasive urothelial carcinoma reduced the incidence of HER-2 expression.

HER-2 overexpression in high grade recurrent tumours implicates poor prognosis, as these tumours are more aggressive, have higher likelihood of lymph node metastases, this will alter surgical treatment and have greater probability of disease progression. ${ }^{33}$

HER-2/Neu overexpression can also be used to distinguish reactive atypia from carcinoma in situ. ${ }^{34}$ Flat urothelial lesions like urothelial dysplasia, flat urothelial hyperplasia, reactive urothelial atypia of unknown significance and urothelial carcinoma in situ are at times difficult to distinguish. HER-2/neu can be added to a panel of CK20 and p53 to help to differentiate reactive atypia from carcinoma in situ in difficult cases. Positive staining for at least two of the three antibodies [CK 20, P53 and HER2/Neu] is strongly associated with carcinoma in situ (CIS). However, the histologic findings should be a primary determinant in the diagnosis of flat urothelial lesions with immunohistochemistry playing a supportive confirmatory role. Carcinoma in situ and low grade urothelial carcinoma express HER-2 and as the tumour progresses to high grade HER-2 expression loses/decreases.

HER-2 overexpression alteration may be associated with particular morphological features as seen in carcinoma breast and colon. ${ }^{35,36}$ The morphological features seen in HER-2 amplified tumours are micropapillary growth pattern, morphological heterogeneity and intratumoural and peritumoural inflammatory infiltrate.37,14 Micropapillary urothelial carcinoma is a unique variant of urothelial carcinoma that comprises $0.7 \%-6 \%$ of all cases of urothelial cancers. $38,39,40$ What proportion of micropapillary urothelial carcinoma express HER-2 is not well established, perhaps three-quarters of them, the range varying widely in different studies. ${ }^{37,33}$ Another feature exhibited by these tumours is a significantly higher morphologic heterogeneity reflected by a higher number of subtype components per tumour. For molecular targeted therapy, pathologists will have to identify HER-2 overexpressing tumours in near future. This may be by morphology, immunohistochemistry (IHC) or by fluorescent in situ hybridisation (FISH). There are numerous studies available, which have used anti-HER-2 drug trastuzumab alone or in combination with other chemotherapeutic agents. ${ }^{41,42,43}$ Several phase II and even phase III trials are currently investigating the possible benefit of HER-2 targeted therapies for patients with urothelial carcinoma. But role of this drug in treatment of urothelial carcinoma is not well established. ${ }^{8}$

\section{CONCLUSION}

In conclusion about three-quarters of urothelial carcinoma overexpress HER-2 and this is very promising for molecular targeted therapy and moreover HER-2 overexpression also has prognostic and diagnostic significance. We propose that immunohistochemistry for HER-2 protein should be incorporated into the routine surgical pathology sign out of urothelial carcinoma.

\section{REFERENCES}

[1] Ferley J, Soerjomataram I, Ervik M, et al. GLOBOCAN 2012 V1.0 Cancer incidence and mortality worldwide: IARC Cancer Base No. 11. Lyon, France: International Agency for Research on cancer, 2013. http:// globcan.iarc.fr

[2] Epstein JI, Amin MB, Reuter VR, et al. The World Health Organization/ International Society of Urological Pathology consensus classification of urothelial (transitional cell) neoplasms of the urinary bladder. Bladder Consensus Conference Committee. Am J Surg Pathol 1998;22(12):1435-48.

[3] Oyasu R. The World Health Organization and International Society of Urological Pathology classification and two number grading system of bladder tumors. Cancer 2000;88(7):1509-12.

[4] Reuter VR, Epstein JI, Amin MA, et al. A newly illustrated synopsis of the The World Health Organization/International Society of Urological Pathology (WHO/ISUP) consensus classification of urothelial( transitional-cell ) neoplasms of the urinary bladder. J Urol Pathol 1999;11:1-28.

[5] Montironi R, Lopez-Beltran A. The 2004 WHO classification of bladder tumors: a summary and commentary. Int J Surg Pathol 2005;13(2):143-53.

[6] Gorin MA, Ayyathurai R, Soloway MS. Diagnosis and treatment of bladder cancer: how can we improve? Postgrad Med 2012;124(3):28-36.

[7] Cormio L, Tolve I, Annese P, et al. Altered p53 and pRb expression is predictive of response to BCG treatment in T1G3 bladder cancer. Anticancer Res 2009;29(10):4201-4.

[8] Ikeda S, Hansel DE, Kurzrock R. Beyond conventional chemotherapy: emerging molecular targeted and immunotherapy strategies in urothelial carcinoma. Cancer Treat Rev 2015;41(8):699-706.

[9] Hollenbeck BK, Dunn RL, Ye Z, et al. Delays in diagnosis and bladder cancer mortality. Cancer 2010;116(22):5235-42. 
[10] Porter MP, Kerrigan MC, Donato BM, et al. Patterns of use of systemic chemotherapy for Medicare beneficiaries with urothelial bladder cancer. Urol Oncol 2011;29(3):252-8.

[11] Calabro F, Sternberg CN. Neoadjuvant and adjuvant chemotherapy in muscle - invasive bladder cancer. Eur Urol 2009;55(2):348-58.

[12] Von der Maase H, Hansen SW, Roberts JT, et al. Gemcitabine and cisplatin versus methotrexate, vinblastine, doxorubicin and cisplatin in advanced or metastatic bladder cancer: results of a large, randomized, multinational, multicentre, phase III study. J Clin Oncol 2000;18(17):3068-77.

[13] Von der Maase H, Senglov L, Roberts JT, et al. Long term survival results of a randomized trial comparing gemcitabine plus cisplatin, with methotrexate, vinblastine, doxorubicin plus cisplatin in patients with bladder cancer. J Clin Oncol 2005;23(21):4602-8.

[14] Tschui J, Vassella E, Bandi N, et al. Morphological and molecular characteristics of HER2 ampilified urothelial bladder cancer. Virchows Arch 2015;466(6):703-10.

[15] Schechter AL, Stern DF, Vaidyanathan L, et al. The Neu oncogene: an erb-B-related gene encoding a 185,000Mr tumor antigen. Nature 1984;312(5994):513-6.

[16] Zwick E, Bange J, Ullrich A. Receptor tyrosine kinase signalling as a target for cancer intervention strategies. Endocr Relat Cancer 2001;8(3):161-73.

[17] Lenferink AE, Busse D, Flanagan WM, et al. ErbB2/neu kinase modulates cellular p27(Kip1) and cyclin D1 through multiple signaling pathways. Cancer Res 2001;61(17):6583-91.

[18] Yarden Y, Sliwkowski MX. Untangling the ErbB signalling network. Nat Rev Mol Cell Biol 2001;2(2):127-37.

[19] Wen XF, Yang G, Mao W, et al. HER2 signalling modulates the equilibrium between pro-and antiangogenic factors via distinct pathways: implications for Her2-targeted antibody therapy. Oncogene 2006;25(52):6986-96.

[20] Nicholson RI, Gee JM, Harper ME. EGFR and cancer prognosis. Eur J Cancer 2001;37( Suppl 4): S9-S15.

[21] Slamon DJ, Clark GM, wong SG, et al. Human breast cancer: correlation of relapse and survival with amplification of the HER-2/neu oncogene. Science 1987;235(4785):177-82.

[22] Tinoco G, Warsch S, Gluck S, et al. Treating breast cancer in the $21^{\text {st }}$ century: emerging biological therapies. J Cancer 2013;4(2):117-32.

[23] Smyth EC, Cunningham D. Targeted therapy of gastric cancer. Curr Treat Options Oncol 2012;13(3):377-89.

[24] Caner V, Turk NS, Duzcan F, et al. No strong association between HER-2/neu protein overexpression and gene amplification in high- grade invasive urothelial carcinomas. Pathol Oncol Res 2008;14(3):261-6.

[25] Fleischmann A, Rotzer D, Seiler R, et al. Her2 amplification is significantly more frequent in lymph node metastases from urothelial bladder cancer than in the primary tumors. Eur Urol 2011;60(2):350-7.
[26] Hansel DE, Swain E, Dreicer R, et al. HER2 overexpression and amplification in urothelial carcinoma of the bladder is associated with MYC coamplification in a subset of cases. Am J Clin Pathol 2008;130(2):274-81.

[27] Lae M, Couturier J, Oudard S, et al. Assessing HER2 gene amplification as a potential target for therapy in invasive urothelial bladder cancer with a standardized methodology: results in 1005 patients. Ann Oncol 2010;21(4):815-9.

[28] Wallerand H, Robert G, Bernhard JC, et al. Targeted therapy for locally advanced and/or metastatic bladder cancer. Prog Urol 2008;18(7):407-17.

[29] Coogan CL, Estrada CR, Kapur S, et al. HER-2/neu protein overexpression and gene amplification in human transitional cell carcinoma of the bladder. Urology 2004;63(4):786-90.

[30] Matsubara H, Yamada Y, Naruse K, et al. Potential for HER-2/neu molecular targeted therapy for invasive bladder carcinoma: comparative study of immunohistochemistry and fluoresecent in situ hybridization. Oncol Rep 2008;19(1):57-63.

[31] Simon R, Atefy R, Wagner U, et al. HER2 and TOP2A coamplification in urinary bladder cancer. Int J Cancer 2003;107(5):764-72.

[32] Morgan BE, Salup R, Morgan MB. Differential C-erb B2 and VEGF expression following BCG immunotherapy in superficial papillary transitional cell carcinoma of the bladder. Urol Oncol 2002;7(2):67-72.

[33] Schneider SA, Sukov WR, Frank I, et al. Outcome of patients with micropapillary urothelial carcinoma following radical cystectomy: ERRBB2 (HER2) amplification identifies patients with poor outcome. Modern Pathology 2014;27(5):758-64.

[34] Jung $\mathrm{S}$, Wu C, Eslami $\mathrm{Z}$, et al. The role of immunohistochemistry in the diagnosis of flat urothelial lesions: a study using CK20, CK5/6, P53, Cd138 and Her2/Neu. Ann Diagn Pathol 2014;18(1):27-32.

[35] Jenkins MA, Hayashi S, O' Shea AM, et al. Colon Cancer Family R. Pathology features in Bethesda guidelines predict colorectal cancer microsatellite instability: a population-based study. Gastroenterology 2007;133(1):48-56.

[36] Mosquera JM, Perner S, Demichelis F, et al. Morphological features of TMPRSS2-ERG gene fusion prostate cancer. J Pathol 2007;212(1):91-101.

[37] Ching CB, Amin MB, Tubbs RR, et al. HER2 gene amplification occurs frequently in micropapillary variant of urothelial carcinoma: analysis by dual-color in situ hybridization. Mod Pathol 2011;24(8):1111-9.

[38] Johansson SL, Borghede G, Holmang S. Micropapillary bladder carcinoma: a clinicopathological study of 20 cases. J Urol 1999;161(6):1798-802.

[39] Alvarado-Cabrero I, Sierra-Santiesteban FI, MantillaMorales A, et al. Micropapillary carcinoma of the urothelial tract. A clinicopathologic study of 38 cases. Ann Diagn Pathol 2005;9(1):1-5. 
[40] Amin MB, Ro JY, el-Sharkawy T, et al. Micropapillary variant of transitional cell carcinoma of the urinary bladder. Histologic pattern resembling ovarian papillary serous carcinoma. Am J Surg Pathol 1994;18(12):1224-32.

[41] Oudard S, Culine S, Vano Y, et al. Multicentre randomized phase II trial of gemcitabine + plantium, with or without transtuzumab, in advanced or metastatic urothelial carcinoma overexpressing Her2. Eur J Cancer 2015;51(1):45-54.
[42] Verdoorn BP, Kessler ER, Flaig TW. Targeted therapy in advanced urothelial carcinoma. Oncology (Williston Park) 2013;27(3):219-26.

[43] Necchi A, Giannatempo P, Paolini B, et al. Immunohistochemistry to enhance progenic allocation and guide decision - making of patients with advanced urothelial cancer receiving first - line chemotherapy. Clin Genitourin Cancer 2015;13(2):171-7. 